\title{
Carcinoma of the cardia and thoracic oesophagus coexisting with and following sliding hiatal hernia and peptic stricture
}

\section{K. MOGHISSI}

From the Humberside Cardiothoracic Surgical Centre, Castle Hill Hospital, Cottingham, N. Humberside

Moghissi, K. (1977). Thorax, 32, 342-345. Carcinoma of the cardia and thoracic oesophagus coexisting with and following sliding hiatal hernia and peptic stricture. A series of 207 cases of carcinoma of the cardia and thoracic oesophagus was reviewed. Ten patients $(9.8 \%$ of those with carcinoma of the cardia) had a hiatal hernia with a coexisting adenocarcinoma. Five other patients $(2 \cdot 4 \%)$ had long-standing records of hiatal hernia, and chronic peptic oesophagitis with stricture before the development of carcinoma. In the cases of hiatal hernia coexisting with carcinoma, there is insufficient evidence of the hernia predisposing to carcinoma. The relationship is thought to be purely coincidental. However, malignant changes may occur in long-standing cases of chronic oesophagitis with peptic stricture.

The association between sliding hiatal hernia and carcinoma of the cardia and thoracic oesophagus has been the subject of sporadic publications in recent years (Feldman and Myers, 1952; Smithers, 1955; Bockus, 1963; Grimes and Zboralske, 1968; Mayer et al., 1976).

The reports are vague in distinguishing between two aspects of this association which are important, namely (1) the coexistence of sliding hiatal hernia and carcinoma, and (2) the development of carcinoma in long-standing cases of hiatal hernia and gastro-oesophageal reflux with peptic stricture.

The purpose of this paper is to present a review of our series of patients with carcinoma of the cardia and thoracic oesophagus, either coexisting with hiatal hernia or following a previously diagnosed hiatal hernia with chronic peptic oesophagitis and stricture. In the light of this review we will discuss the importance of this differentiation, the possible role played by hiatal hernia in carcinoma formation, and the practical application of the association of hiatal hernia and carcinoma.

At the outset it is necessary to define the term coexistence. We have adopted two criteria for defining the coexistence of hiatal hernia and carcinoma, both of which must be present-first, the presence of carcinoma in the region of the cardia or within a radiologically demonstrable sliding hiatal hernia, and second, the diagnosis of carcinoma being made at the same time as that of hernia or after a short interval (not exceeding 18 months).

\section{Patients}

In the course of five-and-a-half years (October 1970-March 1976) 207 cases of carcinoma of the cardia and thoracic oesophagus were treated in our $\delta$ department. One hundred and eleven of these were carcinomas of the cardia. In the same period 253 cases of hiatal hernia with or without stricture were treated surgically. Ten patients (group 1) had a carcinoma coexisting with a sliding hiatal hernia. In five others (group 2), carcinoma was preceded O by long-standing symptoms of hiatal hernia with $\tilde{O}$ evidence of chronic oesophagitis and peptic N stricture.

GROUP 1

The clinical data of group 1 patients are presented $\stackrel{\odot}{\rightarrow}$ in Table 1 . The presenting symptoms were those $\square$ of hiatal hernia with typical reflux oesophagitis

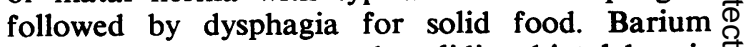
examination demonstrated a sliding hiatal hernia $\underset{\mathbb{Q}}{\mathbb{Q}}$ in each case. In seven patients there was also a filling defect or evidence of a stricture. Oesophagoscopy and biopsy were diagnostic of adeno- 
Table 1 Group 1 patients: clinical findings

\begin{tabular}{|c|c|c|c|c|c|c|}
\hline Case & Age & Sex & Presenting symptoms & Barium swallow & Oesophagoscopy & Biopsy \\
\hline 1 & 65 & $\mathbf{F}$ & Heartburn, dysphagia & $\mathbf{H H}+$ reflux & $\begin{array}{l}\text { Tumour +-itis } \\
30 \mathrm{~cm}\end{array}$ & Adeno \\
\hline 2 & 64 & $\mathbf{M}$ & Retrosternal pain, dysphagia & HH & $\begin{array}{l}- \text { itis + ulceration } \\
36 \mathrm{~cm}\end{array}$ & Adeno \\
\hline 3 & 67 & $\mathbf{M}$ & Heartburn, dysphagia & HH + filling defect & $\begin{array}{l}\text { Tumour +-itis } \\
33 \mathrm{~cm}\end{array}$ & Adeno \\
\hline 4 & 72 & $\mathbf{F}$ & Heartburn, dysphagia & $\mathbf{H H}+$ stricture & $\begin{array}{l}\text {-itis + ulceration } \\
31 \mathrm{~cm}\end{array}$ & Adeno \\
\hline 5 & 68 & $\mathbf{M}$ & Heartburn, dysphagia & HH + ulceration & $\begin{array}{l}\text { Tumour } \\
40 \mathrm{~cm}\end{array}$ & Adeno \\
\hline 6 & 57 & $\mathbf{M}$ & Retrosternal pain, dysphagia & $\mathbf{H H}+$ stricture & $\begin{array}{l}\text { Tumour } \\
40 \mathrm{~cm}\end{array}$ & Adeno \\
\hline 7 & 73 & $\mathbf{M}$ & Heartburn, dysphagia & $\mathbf{H H}+$ filling defect & $\begin{array}{l}\text {-itis + ulceration } \\
36 \mathrm{~cm}\end{array}$ & Adeno \\
\hline 8 & 68 & $\mathbf{M}$ & Heartburn, dysphagia & HH + stricture & $\begin{array}{l}\text {-itis + ulceration } \\
36 \mathrm{~cm}\end{array}$ & Adeno \\
\hline 9 & 67 & $\mathbf{M}$ & Heartburn, dysphagia & $\mathbf{H H}$ + stricture & $\begin{array}{l}\text { Tumour } \\
40 \mathrm{~cm}\end{array}$ & Adeno \\
\hline 10 & 55 & $\mathbf{M}$ & Dysphagia & HH + stricture & $\begin{array}{l}\text { Tumour } \\
38 \mathrm{~cm}\end{array}$ & Adeno \\
\hline
\end{tabular}

HH = hiatal hernia; -itis =oesophagitis; Adeno = adenocarcinoma .

carcinoma in every patient in this group. All 10 patients had a resection of the growth with reconstruction of the alimentary tract.

\section{GROUP 2}

Table 2 summarises the clinical data of the five patients in this group. Each patient had had a long-standing hiatal hernia for 3 to 14 years preceding the development of carcinoma. They were also known to have had a peptic stricture proved radiologically, endoscopically, and histologically for 3 to 15 years. Three patients were known to our department for six, seven, and nine years respectively, attending regularly for oesophagoscopy and dilatation. Of these three, two patients were not offered reconstructive surgery because of their poor general condition. One patient refused surgery. When carcinoma was diagnosed, in three patients only palliative surgery in the form of intubation could be undertaken. In the remaining two patients, dysphagia was treated by palliative dilatation.

Table 2 Group 2 patients: clinical findings

\begin{tabular}{|c|c|c|c|c|}
\hline \multirow{2}{*}{ Case } & \multicolumn{2}{|c|}{ Age/Sex } & \multirow{2}{*}{$\begin{array}{l}\text { Original diagnosis, date } \\
\mathrm{HH}+\text { stricture, } 1963 \\
34 \mathrm{~cm}^{*}\end{array}$} & \multirow{2}{*}{$\frac{\text { Final diagnosis, date }}{\text { Adenocarcinoma, } 1972}$} \\
\hline & 63 & $\mathbf{M}$ & & \\
\hline 2 & 72 & $\mathbf{M}$ & $\begin{array}{l}\mathrm{HH}+\text { stricture, } 1968 \\
33 \mathrm{~cm}^{*}\end{array}$ & Adenocarcinoma, 1975 \\
\hline 3 & 69 & $\mathbf{M}$ & $\begin{array}{l}\text { HH + stricture, } 1969 \\
34 \mathrm{~cm}^{*}\end{array}$ & $\begin{array}{l}\text { Squamous-cell } \\
\text { carcinoma, } 1972\end{array}$ \\
\hline 4 & 66 & $\mathbf{F}$ & $\begin{array}{l}\mathrm{HH}+\text { oesophagitis, } 1960 \\
\text { + stricture } \\
39 \mathrm{~cm}^{*}\end{array}$ & $\begin{array}{l}\text { Squamous-cell } \\
\text { carcinoma, } 1975\end{array}$ \\
\hline 5 & 80 & $\mathbf{F}$ & $\begin{array}{l}\mathrm{HH}+\text { stricture, } 1970 \\
29 \mathrm{~cm}^{*}\end{array}$ & $\begin{array}{l}\text { Squamous-cell } \\
\text { carcinoma, } 1975\end{array}$ \\
\hline
\end{tabular}

*From upper alveolus; $\mathrm{HH}=$ hiatal hernia.

\section{Discussion}

The relationship between hiatal hernia and carcinoma of the cardia and thoracic oesophagus has been questioned since Hill's (1870) original publication. In a recent paper, Mayer et al. (1976) found 103 well documented cases of carcinoma of the cardia with hiatal hernia and added 11 of their own. However, these 114 do not include cases of hiatal hernia with carcinoma of the thoracic oesophagus.

A review of published work reveals several important points, of which the most relevant is the possible role that hiatal hernia and gastrooesophageal reflux play in the development of carcinoma. In order to suggest any possible aetiological relationship it is essential to differentiate between carcinoma coexisting with a sliding hiatal hernia and carcinoma following a long-standing hernia with chronic oesophagitis and stricture. The 10 cases in group 1 are examples of carcinoma coexisting with hiatal hernia. Only one patient gave a history of heartburn for a period longer than 18 months. The remainder gave a short history (3-4 months) of heartburn and reflux oesophagitis. In these 10 patients, it is impossible to incriminate the hernia as a predisposing factor in the development of carcinoma as the existence of the hernia could be the cause or the effect of the carcinoma, or merely a coincidence. The question arises whether the incidence of carcinoma is higher in patients with sliding hiatal hernia than in those without a hernia, so that statistically hiatal hernia might be shown to predispose to carcinoma development. Opinions are divided with conflicting statistical evidence. Feldman and Myers (1952) 
and Bockus (1963) suggest that the coexistence of the conditions is a matter of chance and they present statistical evidence to substantiate their views. Smithers (1955) and Mayer et al. (1976) adopt the opposite view, also supported by statistical analysis. In our 253 cases of hiatal hernia there were 10 cases of carcinoma of the cardia, an incidence of $3.9 \%$. The high incidence of carcinoma in our hiatal hernia patients is probably not an indication of any aetiological relationship, because only hernia cases requiring investigation and surgical treatment are referred to us, and these represent a small proportion of the total number of hiatal hernia cases. We therefore believe that the coexistence of hiatal hernia and carcinoma is purely coincidental.

While statistical studies cannot provide decisive evidence of a causative role for hiatal hernia in carcinoma formation, they provide important information relevant to the management of patients with hiatal hernia. Two types of statistical review may be considered: first, the incidence of hiatal hernia in patients with carcinoma of the cardia collected from published series and presented in Table 3; and second, the incidence of carcinoma of the cardia in patients with hiatal hernia, presented in Table 4. From these tables one can conclude that in a number of patients with symptoms and signs of hiatal hernia (in our series $3.9 \%$ ) carcinoma of the cardia may also be present. The radiological findings of a hiatal hernia in patients under investigation for carcinoma of the cardia should not distract the clinician's attention, as some cases of carcinoma of the cardia (in our

Table 3 Incidence of hiatal hernia in patients with carcinoma of the cardia

\begin{tabular}{lcccc}
\hline Author & Date & $\begin{array}{l}\text { No. of } \\
\text { patients } \\
\text { with } \\
\text { carcinoma }\end{array}$ & $\begin{array}{l}\text { No. } \\
\text { found to } \\
\text { have } \boldsymbol{H H}\end{array}$ & Incidence \% \\
& & & & \\
\hline Adler and Rodriguez & 1959 & 73 & 6 & $8 \cdot 2$ \\
Tanner and Hardy & 1970 & 48 & 9 & $18 \cdot 0$ \\
Mayer et al. & 1976 & 73 & 11 & $14 \cdot 1$ \\
Present report & & 110 & 10 & $9 \cdot 8$ \\
\hline
\end{tabular}

Table 4 Incidence of carcinoma of the cardia in patients with hiatal hernia

\begin{tabular}{lccll}
\hline Author & Date & $\begin{array}{l}\text { No. of } \\
\text { patients } \\
\text { with a } \\
\text { HH }\end{array}$ & $\begin{array}{l}\text { No. } \\
\text { found to } \\
\text { have } \\
\text { carcinoma }\end{array}$ & Incidence \% \\
\hline Feldman and Myers & 1952 & 110 & 3 & $2 \cdot 73$ \\
Adler and Rodriguez & 1959 & 814 & 21 & $2 \cdot 5$ \\
Mayer et al. & 1976 & 1476 & 11 & 0.075 \\
Present report & & 253 & 10 & 3.9 \\
\hline
\end{tabular}

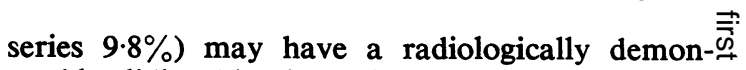
strable sliding hiatal hernia.

The predominance of males over females in our $\frac{\bar{\sigma}}{\bar{m}}$ 10 cases (Table 1) is interesting as the incidence $\frac{\text { ? }}{\sigma}$ of hiatal hernia is usually higher in females.

Group 2 patients, who form $2.4 \%$ of all the carcinoma cases reviewed in this series, present $a \vec{\circ}$ different basis for discussion. In these five patients,, there was a definite, long-standing hiatal hernia $\vec{\omega}$

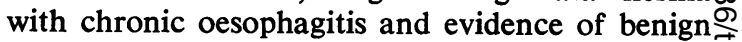
peptic stricture proved endoscopically and histo- $\vec{x}$ logically by repeated biopsies taken by different endoscopists. The interval between the original $\omega$ biopsies showing a benign stricture and the final $\omega$ ones showing malignant transformation was long $\mathrm{N}$ enough (over 3 years) to dismiss the possibility of 음 an overlooked coexistence. Therefore the questionof hiatal hernia with stricture predisposing to cancer formation in these patients can be given $\Phi$ serious consideration. However, if chronic peptic $\vec{\theta}$ stricture is to be incriminated in cancer develop- $V$ ment, one would expect to find more recorded cases.

It may be that cases of chronic oesophagitis with stricture are usually treated surgically and that only those who are not so treated (such as our group 2 patients) are subject to malignant $\frac{\varrho}{\vec{F}}$ change.

It is interesting that, of the five patients in group 2, three developed a squamous-cell carcinoma and two an adenocarcinoma. We cannot provide a satisfactory explanation for this. However, while a squamous-cell carcinoma would arise from the oesophageal mucosa, the adenocar- $-\frac{\times}{\circ}$ cinoma could have developed from the herniated 3 gastric mucosa or a columnar-epithelial-lined oesophagus.

We believe that the presence of carcinoma co-o existing with hiatal hernia is coincidental. However, malignant changes may occur in cases of $\frac{D}{2}$ chronic peptic stricture. These patients, when treated conservatively, may be at risk because of $O$ the difficulty and delay in the diagnosis of $N$ malignancy.

I am grateful to Mrs. C. Lutley for assistance in the preparation of this paper, and to Miss L. $\frac{\mathbb{\Phi}}{\mathbb{Q}}$ Dennis for secretarial help.

\section{References}

Adler, R. H. and Rodriguez, J. (1959). The association of hiatus hernia and gastroesophageal malig- $\varrho$ nancy. Journal of Thoracic Surgery, 37, 553-569. श Bockus, H. L. (1963). Gastroenterology, 2nd edition, $\bigcirc$ Volume 1, p. 160. W. B. Saunders, Philadelphia. 
Feldman, M. and Myers, P. (1952). The coexistence of carcinoma of the stomach and esophageal hiatus gastric hernia. American Journal of Medical Science, 224, 519-521.

Grimes, O. F. and Zboralske, F. F. (1968). Carcinoma in association with hiatal hernia. Journal of Thoracic and Cardiovascular Surgery, 55, 30-41.

Hill, J. D. (1870). True diaphragmatic hernia with stricture of the oesophagus. Transactions of the Pathological Society of London, 21, 154-158.

Mayer, D. A., Gray, G. F., Teixidor, H. S., and Thorbjarnarson, B. (1976). Carcinoma of the gastric cardia and hiatal hernia. Journal of Thoracic and Cardiovascular Surgery, 71, 592-599.
Smithers, D. W. (1955). The association of cancer of the stomach and oesophagus with herniation at the oesophageal hiatus of the diaphragm. British Journal of Radiology, 28, 554-564.

Tanner, N. C. and Hardy, K. J. (1970). Hiatus hernia. A follow-up of 53 operations. British Journal of Surgery, 57, 131-134.

Requests for reprints to: K. Moghissi, FRCS, Cardiothoracic Surgical Unit, Castle Hill Hospital, Castle Road, Cottingham, N. Humberside HU16 5JQ. 